\title{
Yours ever (well, maybe): studies and signposts in letter writing
}

\author{
Richard J. Cox
}

Published online: 6 July 2010

(C) Springer Science+Business Media B.V. 2010

\begin{abstract}
Electronic mail and other digital communications technologies seemingly threaten to end the era of handwritten and typed letters, now affectionately seen as part of snail mail. In this essay, I analyze a group of popular and scholarly studies about letter writing-including examples of pundits critiquing the use of e-mail, etiquette manuals advising why the handwritten letter still possesses value, historians and literary scholars studying the role of letters in the past and what it tells us about our present attitudes about digital communications technologies, and futurists predicting how we will function as personal archivists maintaining every document including e-mail. These are useful guideposts for archivists, providing both a sense of the present and the past in the role, value and nature of letters and their successors. They also provide insights into how such documents should be studied, expanding our gaze beyond the particular letters, to the tools used to create them and the traditions dictating their form and function. We also can discern a role for archivists, both for contributing to the literature about documents and in using these studies and commentaries, suggesting not a new disciplinary realm but opportunities for new interdisciplinary work. Examining a documentary form makes us more sensitive to both the innovations and traditions as it shifts from the analog to the digital; we can learn not to be caught up in hysteria or nostalgia about one form over another and archivists can learn about what they might expect in their labors to document society and its institutions. At one time, paper was part of an innovative technology, with roles very similar to the Internet and e-mail today. It may be that the shifts are far less revolutionary than is often assumed. Reading such works also suggests, finally, that archivists ought to rethink how they view their own knowledge and how it is constructed and used.
\end{abstract}

R. J. Cox (ه)

School of Information Sciences, University of Pittsburgh, Pittsburgh, PA, USA

e-mail: rjcox111@comcast.net 
Keywords Letter writing - Electronic mail - Archival knowledge ·

Archival history

\section{Introduction: when the mail arrives}

It has been a very long time since I received in the mail a handwritten or typed personal letter. It is not difficult, of course, to remember when I last received an e-mail message-it was mere seconds ago. To experience a traditional letter, one visits an archive, museum, auction house, or an antique market. But I don't want to seem too sentimental. Our newer digital means of communication are remarkable. Recently, I received an e-mail from a friend whom I had not seen for more than a decade who found me by doing a Web search combining my name and "archives." I do not believe this was any less meaningful or emotional than if it had occurred via the delivery of a traditional letter. I was just happy to make contact and to go from there.

The present rarity of new traditional correspondence is such that scholars often pause to comment on their interaction with such documents. Garvey (2009) writing about the iconic style manual by Strunk and White and using E. B. White's rich personal papers at Cornell University, worries about "what we lost when we gave up writing letters" (p. xxli). Saltzman (2008), studying the art trade between Europe and America in the Progressive Era, comments how the practices of museums, dealers, and collectors are captured in letters and cables and "unveil the combination of ego, idealism, and ambition" involved in such collecting (p. 7). Darnton (2009), on the possibilities of understanding the history of books, underscores the unique value of letters in publishers' archives when they survive (pp. 61, 197). Such observations have been intensified by a sense that e-mail and other digital surrogates for the letter are on the rise, and that they are far more fragile and less informative than the traditional letter. Literary scholar Solomon (1998) suggests, "aside from conveying information, e-mail commonly serves as a way of keeping in touch with little effort. A letter by its inherent nature indicates thought - and thought is always improved by careful writing. E-mail is inherently anticontemplative" (p. 320). For such reasons, a new generation of scholars and social critics (public scholars) is beginning to investigate the nature of personal correspondence, both to understand the past of this documentary form and its future among new digital forms. What follows is a discussion of a sampling of recent publications about letter writing, considering what they tell us about this documentary genre, why archivists should pay attention to them, how these publications connect to archival scholarship, and what they suggest about the possibilities for new research.

This scholarship is particularly relevant for both experienced archivists (who should be observant whenever interest in a documentary form appears) and present archives students, who seem to be younger and younger every year, and who may have little personal experience with the traditional letter. What all know is that we may be living in the most communicative generation in world history, easily represented by the density of e-mail: we receive 35 trillion messages a year and 600 
million e-mails are sent every $10 \mathrm{~min}$. There is so much e-mail that it disrupts our normal day innumerable times (if we allow it). About $40 \%$ of a typical workday is occupied in the use of e-mail, with the normal worker fielding 200 e-mails a day, many of which are spam (over 100 billion spam messages are generated each day) (Freeman 2009, pp. 4, 5, 12, 20, 122). There is no place we can go that we don't find most people staring at computer screens or where we don't face the temptation of opening up a computer to check our own messages. Airports, hotel rooms, vacation beaches, baseball games, church pews, and classrooms are just another place to sit and catch up with our virtual friends and colleagues (while sometimes ignoring those sitting next to us).

\section{The e-mail tsunami}

For every innovative digital information system, there are both praises and polemics. Literary critic John Freeman's book about e-mail is an example of the latter, ticking off every negative aspect of e-mail, real and, imagined. He notes that because of 24/7 technologies such as e-mail, we are working longer, are always connected, and are always working (Freeman 2009, p. 104). Moreover, Freeman contends that e-mail is addictive, creating both the "most distraction-prone workplace in the history of mankind" (p. 140) and a passive society relying on faulty information (pp. 185, 196). Freeman, like others who reflect on e-mail and its challenges and implications, puts this form of communication into the context of the history of letter writing, surmising that "handwritten letters had their own signature of authenticity" (p. 48) as well as providing an important sense of intimacy: "Letters that emerge from the dust of antics and lockboxes are like time capsules; they preserve the concerns and worries and passions or our loved ones at the moment they were written." Freeman believes that "even if e-mails are preserved, though, they may not tell us as much as letters" (p. 180). However, this is a claim engaging new scholars to study older correspondence systems and their successors.

\section{Etiquette in the midst of the storm}

One of the measures about how the continuing shift from snail mail to e-mail has made us uneasy can be seen in the growing number of etiquette manuals addressing digital messaging and what they have to say about the creation and management of personal correspondence (as will be discussed later, such manuals are not new, and earlier versions have been useful historical documents for studying older forms of letter writing). In one recent example, O'Shaughnessy (2008) contends, "Evidence is mounting that although e-mail is an undeniable presence in today's world, its effectiveness is limited when clear and meaningful expression is the desired goal" (pp. 13-14; for other recent examples see Florey 2009; Shepherd and Hogan 2008).

Those who write such guides today believe that our digital means of communication have weakened our communication effectiveness and "enhanced" the handwritten note "because it is rare, more personal, and more meaningful, and is 
thus appreciated as a gift more than ever" (O'Shaughnessy 2008, p. 16) and seemingly enables us to reveal more about ourselves (O'Shaughnessy 2008, pp. 19, 37). Whether this is merely wishful thinking will require far more analysis, but it does suggest interesting possibilities for research about the nature of shifts occurring in documentary forms and what they reveal about contemporary society. These manual writers often reveal a sentimental fascination with handwriting, leading to notions that some topics are just not intended to be communicated in e-mail: "Although there is indeed a place for electronic communication, letters of any sort of sentiment are certainly not an occasion for e-mail. Notes expressing condolence, gratitude, and reconciliation demand a hand! The qualities of a handwritten letter provide an essential human quality that lends deeper and essential meaning to our missives" (O'Shaughnessy 2008, p. 60). Nearly magical attributes are assigned to the art of writing a letter, including keeping families together (O'Shaughnessy 2008, p. 16) and giving children the "life skills required to know and express themselves more fully, to appreciate others more deeply, and to make a profound connection between the two" (O'Shaughnessy 2008, p. 117). It is easy to dismiss such generalizations, but there is nothing particularly new with this publication genre. Examining advice manuals of a century or two ago provides evidence of attitudes about gender roles, vocation, society, and other features; so too will recent manuals be drawn on as evidence about the technologies of communication in the digital era. Archivists should pay attention to the continuing publication of such etiquette and self-help manuals as an aid to understanding modern documentation.

In O'Shaughnessy's (2008) advice book (as well as others of this genre), we find many interesting observations about the nature and utility of electronic communications even while rhapsodizing about the pleasures of the older handwritten or typewritten epistle. She acknowledges that electronic messages can have "soul" and be effective (O'Shaughnessy 2008, p. 144). And it is often "soul" that archivists and researchers in archives are looking for in their efforts, even if we admit that etiquette manuals, intending both to instruct and inspire, also can become too effusive in the descriptions of the values of documentary forms such as letter writing (O'Shaughnessy 2008, pp. 150-151). While it is easy to dismiss such commentary as wishful thinking or unsubstantiated opinion, this also does capture something of an ongoing fascination with letter writing as a process coming from deep in our psyche. Letter writing, thousands of years old and the generator of countless examples housed safely in archives, jammed into attics, and, often featured in auctions and exhibitions and popular television shows such as Antiques Roadshow, is a function continuing to attract the scrutiny of scholars in a variety of ways.

\section{Enthusiasm for the letter}

Thomas Mallon, essayist, novelist, and literary scholar-what one calls a public scholar, has written an interesting reflection on letter writing. His book is "organized roughly around the circumstances motivating" the generation of letters. Mallon refers to his book as a "judgmental survey" being "offered not as an exercise in nostalgia but a series of glimpses into a still-living literature" (p. 11). 
The notion of letter writing as being a still-living documentary form is compelling, another way of seeing its durability even with the advent of digital surrogates, but it is Mallon's view of letter writing as constituting a literature that is even more interesting (archivists tend not to view documents as literature but as evidence).

Mallon considers the nature of letter writing by this genre's primary topics, such as absence, friendship, advice, complaint, love, spirit, confession, war, and prison. Mallon is unapologetic about his sentimentality concerning this documentary form, because of how he views the importance of the letter: "Like deeds and wills, letters were instruments that helped a man to hold his place in the turbulent medieval world" (as well as in subsequent periods) (p. 17). Mallon provides detailed descriptions of many famous and infamous letter writers, seeking to demonstrate why we remain so interested in reading and preserving such documents. We gain insights into how such documents are created and maintained. Why do some letters survive, and others disappear: "It's an irony that besets epistolary relationships: the letters of the disorderly person or the wanderer... wind up being saved and filed and organized; what's written by the correspondent with regular habits disappears into the other person's chaos" (Mallon 2009, p. 69). Mallon tracks the evolution of attitudes about letter writing, reflecting, as just one example, on advice columnists in mass circulation magazines responding to letter writers revealing their most intimate problems and suggesting the utility of the epistolary form (p. 111).

Where Mallon shines is with his comparison of letters to other documentary forms and his ability to reach a broader readership. Those who have read his earlier book on diaries (Mallon 1984) will recognize in Yours Ever both his approach and his understanding of the diary, enabling him to set up various contrasts with other documentary forms, such as those found in presidential archives (Mallon 2009, pp. 115, 123). Mallon's book, aimed at a popular readership, is also testimony to the lure of letters, our insatiable need to read other people's mail, and, even if indirectly, our impulse to save documents. If a public scholar such as Mallon believes that there is a broad audience for such a book as his, shouldn't archivists also see opportunities to connect with such a readership? Of course, it is possible that those reading about letters won't necessarily connect them to archival repositories and the profession supporting them (they may connect them to old family letters in shoeboxes lining attic, basement, and closet shelves).

\section{Scholarly reflections}

Letters have always been a temptation, as revealing signposts into the past, to historians and other scholars. Increasingly, letter writing has become a topic for academic study, as three examples here will demonstrate. Goodman's (2009) study of women letter writers in eighteenth century France testifies to the possibilities the penning of epistles provided women, this scholar believing that "writing letters and engaging in correspondence helped women to achieve moments and degrees of autonomy within the context of human relationships-from family and friendship to social and gender systems, systems that were becoming modern as they were themselves" (p. 3). Goodman examines four women who regularly used their 
epistolary practices to position themselves in the world (p. 5). This historian discovers both the individuality of each of the letter writers and the limitations of ever fully understanding letter writing as a general practice concluding that the "closer one looks at particular women and their letters, the more individual they become, the less typical they seem: to look for the typical is to lose the individual." Goodman seeks "to situate the letters of these individual women within two frameworks: the educational theories and practices that shaped how young ladies were taught to become letter writers; and the consumer revolution that shaped the material world they entered as letter writers" (p. 7). It is an approach most recent scholars examining letter writing have adopted.

What is interesting about Goodman's study is her analysis of not just the actual letters, but the tools and material expressions used to create these documents, where she perceives the "power of writing" extending "from its dual nature as both a material and an intellectual practice" (p. 9). Goodman examines the nature of paper, pens, inkstands, and writing desks; how images of writing are depicted in portraits; and the material culture documenting the educational aspects of teaching writinginvolving language instruction, the role of writing masters, and penmanship. Examining the proliferation of consumer goods-pens, ink, paper, seals, sealing wax, desks, and inkstands-we discover a major transformation in the importance of letter writing and one that because it continues to be significant for us today is worth a lengthier quotation:

The shift from secretary (the person) to secretary (the desk) reflected a fundamental change in the practice of writing that entailed a change in both its social meaning and its psychological significance. The creation of the secretary signaled a new authorial need for a personal surface on which to write, as private persons shifted from dictating their letters to a confidential secretary to penning them themselves. What had been two fundamentally different kinds of actions - a noble intellectual or spiritual act of composition and a base mechanical or physical act of inscription - carried out by people of different social status was now integrated into a single practice carried out by a single individual. The transformation of the secretary allowed writing to become fully personal - the expression of one's being or self - by eliminating for the composer the mediation of a servile human being and at the same time empowering the scribe to use his skill and his tools to his own ends rather than someone else's (Goodman 2009, pp. 236-237).

The centrality of importance in the writing of letters for forming character, establishing social status, and shaping personal identity suggests just how new communication technologies in any era assume significance beyond anyone's expectations. It also reminds us how we need to temper the sweeping claims often made by the advocates of new information technologies (such claims naturally accompany the introductions of all new information technologies) that information professionals, such as archivists, often glibly accept.

Another letter-writing study, this one examining it in early America, provides additional insights into the nature of correspondence. Konstantin Dierks, acknowledging the importance of letters as evidence of the past (especially the rich content 
they may provide), also wonders about who were writing letters and their reasons for doing so. To determine this, Dierks visited every major state historical society to examine letters, concluding that letters by ordinary people were not normally collected by such archives until recently; he believes that "letters that do survive are only a tip of the iceberg. Letter writing was far more ubiquitous in eighteenthcentury life than our modern archives can possibly indicate" (Dierks 2009, p. xvi). Such observations about archives by a researcher suggest another reason why archivists need to read such scholarly monographs. In the past, archivists, when considering the value of history for their work portrayed it as building subject knowledge about the content or context of documents; now, however, there is a portion of historical, literary, and cultural studies focusing on the nature of the production of documents such as letters and providing a useful basis for expanded understanding of such documentation. Moreover, when researchers using archival materials comment on the nature of archives, it is not always with the sensitivity and experience that archivists bring to the table; for example, Dierks' comment about the late acquiring of letters seems suspicious, since these historical societies reveled in the collecting of personal and family papers from their start.

Even if some of their observations are flawed (mostly incomplete), these scholars imply new ways of examining archival documentation. Dierks not only studies the actual letters but letter-writing manuals, newspaper advertisements offering letterwriting instruction, fiction, laws, and other evidence to reconstruct what he sees as a "culture of documents" built around paper (and involving printers, bookstores, scrivener offices, libraries, paper mills, and post offices) (p. 4). Paper was the glue tying everything together, enabling the production and maintenance of books, letters, and business and government records and the establishment of bookstores, paper mills, and register offices attesting to a new economy based on emerging communication systems (Dierks 2009, pp. 282-283). It can be difficult for us, at times, to comprehend the importance of paper as an innovative technology since we sometimes avoid looking back into the past to understand communications in earlier eras, instead viewing it progressively (everything is improving) through the lens of our own modern communications systems. For Dierks, deciding to study letter writing reflects a shift in the nature of scholarship itself, observing, "Historians have long mined letters as sources of evidence about the past, but literary scholars have pioneered the study of the letter motif itself" (p. 3). From my vantage as an archival scholar, while understanding such a perspective, I have been less sensitive about such a distinction; my tendency is to probe into any scholarship relating to the nature of documentation (and often, these days, it is difficult to distinguish between historical and literary studies, one field generously borrowing from another). Indeed, we can understand modern archives, even if now struggling with digital documentation, as testimony to an older reliance on paper.

Examining past practices in letter writing often reminds us that our present attitudes and approaches to letter writing and newer versions of this exercise such as e-mail have deep precedents. Letter manuals in the eighteenth century are now seen as aids with an "explicit cultural mission," to assist young middle class men to establish themselves in the economy and social networks of their era by introducing them to "an array of technical skills and a bit of social decorum" (Dierks 2009, p. 73). 
Some day in the future, historians and other scholars will read closely the letter writing and e-mail etiquette manuals and social commentaries of such network technologies of our day, like the older ones described earlier in this essay, for clues to the messages conveyed there about our culture and society (placing the nostalgic use of pen and paper or concerns about personal privacy and ubiquitous networking into a broader range of concerns about individual and family life). They might also examine archival literature, finding aids, and Web sites to understand more fully the means by which archives were created and how and why some letters came to reside in them.

Looking backwards, it is not difficult to determine what we might see in the future. For instance, Dierks' description of eighteenth century correspondence bears uncanny resemblance to e-mail today, focusing on conventions locating "a letter's place in the sequence of outgoing and incoming letters, so as to pinpoint exactly what information it was responding to, and what information it was following upon," seeking to overcome the challenges presented by the "potential lag in transatlantic time - and from the fact that the most recent letter for the writer might not be the most recent letter for the recipient" (p. 83). Does this not sound familiar to how we can build a trail of previous messages when we respond to the most recent message in our e-mail systems? In other words, has technology of the early twenty-first century transformed all that much the conventions of correspondence? Yes, perhaps when we examine text messaging and other venues that produce new systems of abbreviations and writing codes in order to speed up communication, especially since for some (not me, I am too old) e-mail now looks more and more like snail mail.

There are other potential similarities as well between the use of quill pen, paper, and iron ink and the digital technologies today. Gender issues are an example, since letter writing meant business transactions and the "material culture of letter writing... were masculine objects" (Dierks 2009, p. 93). Digital technologies have often been associated with males and business ventures, explaining why schools of information or computer science often must make extra efforts to recruit women as both students and faculty (at least for the more technically oriented fields). Dierks cautions us, however, to rethink the connection of letter writing with technology, and vice versa, namely reminding us that the "social practice of letter writing became enormously popular before it became dependent on technology and unseen institutionalization" (p. 281). Newer forms of correspondence, enabled by new technologies, are not solely determined by the technologies but build on older conventions associated with the letter.

A final recent scholarly treatise about letter writing provides a more blatant homily on how we need to be cautious in embracing new technological innovations as societal transformers. Golden (2009) acknowledges her love of traditional letter writing, seeing that it may be coming to an end because of e-mail, text messaging, and mobile phones. Golden examines the advent of the Penny Post and the use of prepaid postage stamps in Victorian Britain, bringing with them new social relations and representing a "forerunner of computer-mediated communication (CMC) networks" (pp. 3-4). The rapid increase in posted letters, buoyed by multiple daily deliveries of the letters, is no less impressive than what occurred with e-mail a 
century and a half later and studying this communication shift provides "insight into our current love affair with innovative information technology, as well as into the complications and challenges such innovation inevitably brings" (Golden 2009, p. 39). Opening with a detailed history of postal reform and its aims (such as increased literacy and improved morality), Golden identifies the post office as a "frequently visited public place, a social space where men and women in town and city alike came in contact with those whom they might not otherwise encounter" (p. 183). This is changing, of course, as the Internet seems to reduce our reliance on postal deliveries or visits to a physical structure.

Like other recent scholars studying letter writing, Golden uses technology and material culture, along with historical, literary, and visual resources. This historian also looks at letter-writing manuals and writing desks. The manuals "give insight into styles of communication, values, and decorum of a bygone era" (Golden 2009, p. 123). Writing desks in the Victorian era, those devices easy to find in plentiful supply in antique stores today (suggesting how common they were), reinforced the Victorian era's "importance of portability and security to the Victorians" (Golden 2009 , p. 136). The obvious connection in our own day is to the laptop (Golden 2009, p. 239). Golden's book is testimony that understanding the degree in which contemporary information technologies are innovative requires a firm grounding in the history of technologies, their purpose, and their use.

\section{Is there a new discipline of letter-writing studies?}

Examining these three scholarly studies suggests how influential literary and textual studies have become with such documentary sources. Add to these disciplines that of rhetoric and communications studies, with one of its practitioners, Carol Poster, stating, "letter-writing theory is a body of materials in search of a discipline" (Poster and Mitchell 2007, p. 3). Poster may not have looked far enough at other disciplines, since archivists might argue with this, suggesting that archival science could provide such a theoretical framework. However, we know that the scholarship associated with this field has been more inward looking, either considering professional practice issues or the history of its own ideas and institutions (both important topics in their own right). The exception might be the notion of diplomatics, but this older form of archival science has gained little notice by the wider community of scholars. The question lurking is whether archivists should be contributing to such scholarship or merely tracking it and drawing on it for their own work.

Some studies of documentary forms such as letters are showing signs of bridging the gap between archival studies and other disciplines, seeking to answer questions that are fundamentally archival in nature. Historian Gerber (2006) provides an example considering the correspondence of British immigrants to North America in the nineteenth century, and arguing, "immigrant letters are probably the largest single body of the writings of ordinary people to which historians have access" (p. 5). The result is a rich analysis of the role of letter writing, what immigrants wrote about, and how and why the letters survived. Gerber comments on the issue of the survival of these letters, such as the following: "The key to the problem of the 
letter as an artifact of a process of retention and collection ultimately may lie in solving the elusive problem of why some people value the past and the people who inhabit it, when so many people in modern Western societies seem not to do so" (p. 8). In other words, why don't such letters survive, a good topic for more research. Gerber worries about the "representativeness" of the surviving correspondence, since they may be the "artifacts of a process of collecting and archiving letters" by public repositories (p. 62). He wonders if the lack of revealing love letters is because they were part of a self-imposed sense of privacy and never intended to be seen by others (pp. 107-108) and also influenced by an "obscure and highly individualized process of saving, collection, and donation. We seldom know how or why these collections were brought together, and to this extent we cannot know how complete they are" (p. 201). But most archivists probably would contend that such letters are actually quite evident in their repositories and could produce, usually on short notice, examples (as well as provide explanations of how these letters came to reside in archival repositories). One wonders to what degree Gerber tried to find more information, especially from the archivists administering these collections and their own literature, about the provenance, history and preservation aspects of such archival holdings; but we also can read this as a call for archivists to write more directly about how their repositories have been filled. Gerber is sensitive to archival concerns, such as when he describes the challenges the immigrants faced in creating and caring for these letters, noting the short supply of quality paper, the issues of homemade inks, the scraping to produce quill pens, and the difficulty in making corrections (Gerber 2006, pp. 143-144). If an attribute of archival knowledge is expertise about the history and nature of records and recordkeeping systems, then archivists certainly have a responsibility to engage in dialogue with scholars such as Gerber.

Reflecting on the survival of documents is particularly relevant as we leave behind the world of paper texts for the brave new world of digital sources. If it is the case that in the past what survived was often due to chance or heroic rescues by archivists and private collectors, we nevertheless recognize that a healthy portion of the documentary universe remains. So many writing about the digital variation of the documentary universe have been pessimistic, except for some who now see that we could save everything, including another correspondence form, all those e-mails.

\section{Total recall (or total nonsense?)}

We need to balance our reading of new predictions about the utility of information technology, always offered to us with great conviction and certitude, with the messier evidence of how information technologies have operated in the past. Bell and Gemmell's (2009) glimpse into the future of a powerful "e-memory" (p. 4) where "You become the librarian, archivist, cartographer, and curator of your life" (Bell and Gemmell 2009, p. 5). They believe that existing technology enables such an approach and that it is both cost and time effective. This is not science fiction, identifying the basic equipment as including no more than a smart phone, GPS unit, digital camera, personal computer, and Internet connection. 
Obviously, e-mail is part of Total Recall. Bell, inspired by Vannevar Bush's Memex idea, developed MyLifeBits, starting with the simple premise of digitizing to eliminate paper and testing out ideas on himself and his practical needs and expanding to store digitally all his documents in a database with full text indexing and metadata. Bell and Gemmell extend the concept to encompass memory about work, health, learning, and the everyday events of life. They envision "lifelogs will be opened to a trusted historian to excerpt, if not entirely released to the public" (pp. 128-129) leading to a "complete record" and "virtual immortality" (p. 139). It is unclear how this might happen, but it is difficult to imagine how many "historians" will be interested in doing such work or how many archivists could be persuaded to make this a priority. Digital curation, an approach many archivists and historians are exploring, represents a very different agenda involving archival functions such as appraisal (see, for example, Cox 2009).

As in most of Bell and Gemmell's discussion in this book, the details or specifics of such recommendations get fuzzier when we move from merely harnessing the use of existing tools, with recommended uses of avatars after death (p. 154), raising ethical or religious quandaries that are not really considered (especially since the authors believe that there will be societal and peer pressure on individuals to adopt the method, overriding reasons not to create comprehensive digital archivestechnology as social determinant) (p. 21). They do hedge their bets by suggesting that not everything will be public (p. 213) and that new forms of etiquette will be required (p. 15), all while seeing that any political, social, cultural, and ethical barriers are unwarranted and unwise (p. 8). There will be important barriers, of course, as Lanier (2010), a technology designer, gently reminds us, arguing "We have repeatedly demonstrated our species' bottomless ability to lower our standards to make information technology look good. Every instance of intelligence in a machine is ambiguous" (p. 32).

\section{Looking backward}

Reading the emerging scholarship on letter writing and its digital descendants should remind us that some of the attributes we associate with the new digital networks are not particularly new, except in their pervasiveness and speed. Letters, with their ability to break down spatial barriers and in their framing new social conventions and constructing identity and communicating text within those conventions, are ancient (see Morello and Morrison 2007), as are the concept of communication networks. The British Empire, as just one example, built a great system for the study of natural history in the eighteenth century, enabling the gathering of natural history specimens and information about them, the latter through the creation of an elaborate correspondence network (Parrish 2007, pp. 8, 18). The use of correspondence as a main pillar of the natural history network is another reminder about how earlier information societies functioned long before the advent of the computer and what we now consider to be the information society. As time wore on, the use of correspondence became more sophisticated, as the "letters possessed not only evidentiary but also diagnostic force. They would not only reflect 
but reveal what otherwise remained hidden. Letters were to be the proper modern instrument for probing human nature" (Parrish 2007, p. 137). This may explain why digital curation, in its slightly earlier manifestation as data curation, seems so ensconced in scientific research and work. Given the origins of the Internet in the scientific community, it should be no surprise why e-mail would be used in precisely the manner Parrish contends natural history built and used correspondence networks.

The question is how new communications technologies transform letter writing. Deresiewicz (2009) suggests that the changes will be immense, as we move from e-mail to cell phone texting, Facebook pages, and twittering as a means to generate as many friends as possible, even to become celebrities: "Not long ago, it was easy to feel lonely. Now, it is impossible to be alone" (p. B6). Clive Thompson (2010) presents a different perspective, believing that "online communications has helped revive the written word in an otherwise rampantly postprint culture. Because young people conduct a huge chunk of their socializing and self-expression online, they are generating far more prose than any generation before" (p. 12). Reading such assessments opens a window into the possibilities of new research, some of which ought to be conducted by archivists. A small number of archivists exploring e-mail and related networked communications have made surprising conclusions that might surprise those lamenting the demise of older technologies like letter writing, suggesting that e-mail enables contextual information and metadata to be more easily managed than what could be done with traditional correspondence (Hyry and Onuf 1997, p. 38; Gilliland-Swetland 1995, p. 40).

\section{Some concluding thoughts}

Other than the obvious that reading such scholarly and popular literature concerning the nature, construction, and use of various document forms, past and present, can be useful to working archivists and the preparation of new archives faculty, what else can we conclude when reading such publications? Are archivists, if such knowledge is useful, also contributing to such research-or should they contribute?

A quick examination of three leading journals in the field-the American Archivist, Archivaria, and Archival Science - over three recent years (2007-2009) suggests that archivists are actively involved in researching the history and nature of document forms (or, in some cases, publishing the work of others outside the field). In these years, the journals have published articles about Native American archival sources (Mifflin 2009), cell phone records (Caswell 2009), moving images (Ricci 2008), musical audio recordings (Alexander 2008), photographs (Benson 2009; Mifflin, 2007; Murray 2008), literary records (Douglas and MacNeil, 2009), performing arts sources (Jones et al. 2009), tattoos (Wright 2009), theatrical scripts (Davies 2008), and diplomatic archives (Dover 2007). It is difficult to find any issue of these journals not featuring at least one essay discussing a document form, although the tendency of these journals is to focus primarily on issues contributing more to archival application than to understanding records and recordkeeping systems.

In a smaller number of essays, there are efforts to cross over disciplinary boundaries and to examine documentary forms in a manner incorporating historical, 
literary, and archival insights. In the Douglas and MacNeil (2009) study about writers' archives, for instance, we learn that "archivists may act as coaxers, adding new layers of meanings to literary archives through acquisition, arrangement and description, and preservation practices. However, even before a writer's fonds reaches an archival repository, relatives, friends, agents, and executors may participate in the formation of the archive over time, helping to determine its boundaries and contexts, and sometimes even contributing materials of their own" (p. 37). This kind of assessment is a considerable distance from the notion of archivist as neutral observer or objective commentator. Instead, we see archival materials as living, changing entities where the notion of creators is expanded and custodians and users all play continuing roles. Here, a "writer's archive is perhaps best understood as a social and collaborative text rather than a purely psychological one," "an ongoing conversation between the writer and her various selves, between the writer and other interested parties who contribute to the archive, between the writer and the archivist who arranges her papers, and between the writer and each user who encounters her through those papers" (Douglas and MacNeil 2009, p. 39).

Archival knowledge generally builds around the tripartite explanation of theory, methodology, and practice, and it has served us well. Using these three components identifies us as an applied field, with all the infamous tension between archival theory and practice. Reading works by scholars such as Goodman, Dierks, and Golden suggests that something may be missing in the traditional framework for defining archival knowledge. We need something beyond the theory, methodology, and practice aspects of archival knowledge as endorsed by professional associations, such as the Society of American Archivists, in their educational guidelines, perhaps suggested by their allusion to interdisciplinary knowledge (SAA, Guidelines). Wouldn't this merit the inclusion of scholarly research from other fields such as the examples considered in this essay? Knowledge of the profession (including the history of archives and the profession, as well as records and cultural memory) and contextual knowledge (including cultural and social systems) certainly help, but it seems that a fourth leg ought to be added to the table representing archival knowledge. Perhaps we ought to think of theory, methodology, practice, and reflection, the latter being a more focused notion of reading broadly outside the archival community into the research, philosophical, and even public (or popular) scholarship on the nature of records and recordkeeping systems. The purpose of my blog, "Reading Archives," which I ran for two and a half years, until May 2009, was intended to examine scholarly and popular literature discussing archives with an aim of generating discussion about such literature.

Archival knowledge must encompass the kinds of publications examined here. Nonarchivists are grappling with archival topics, and practicing archivists and archival students need to be aware of such work. We have become much more capable of conducting our own research and certainly more sophisticated in our research methodologies (Gilliland and McKemmish 2004), and it is likely that more systematic reading of other forms of archival research both will improve our own work and, perhaps, build connections between archival scholars and other scholars studying archives into new and improved interdisciplinary approaches. This may also make these other researchers more aware of the contributions of archivists to 
advancing our understanding of what records and archives represent. Terry Cook, among the archival ranks, has complained that historians using archives have often not been aware of the work, both practical and scholarly, responsible for assembling archival collections (Cook 2009). This will change as others increase their study of archives and archivists, and archivists and archival educators begin to contribute to this scholarly research and dialogue with others. There is no reason, for example, that both archival scholars and practitioners can't contribute studies about the history and nature of letter writing and subsequent versions such as electronic mail. The methods of conducting such research fall well within the working knowledge of the archival community.

At the least, we can identify, by perusing the kind of literature described in this essay, important research that archivists, ideally in collaboration with other disciplines, can undertake to strengthen their own knowledge. A variety of topics emerge, such as the similarities and differences between traditional letters and electronic mail; whether traditional letter-writing forms are persisting in the digital era; how researchers make use of old letter forms and their digital replacements or successors; the implications of more fully understanding the letter as document on basic archival applications such as appraisal, access, and representation; and the significance of the processes associated with letters being brought into the archives and how this may change if the digital replacements are held in trusted virtual or personal repositories. Fortunately, we are beginning to see evidence of a new scholarship addressing such matters. A collection of essays on the persistence and cultural value and uses of handwriting considers, in true interdisciplinary fashion (contributors include art scholars and artists, experts on law, media studies, literary studies, linguistics, archives, information science and film studies), a variety of cases such as the Anne Frank diaries, digital media and authenticity in scientific communication, diaries and blogs, the identity of signatures and the efforts to find a signature substitute in the digital sphere, the formation of an archive, reading the manuscripts of Marcel Proust's Remembrance of Things Past, the use of signatures in movie and television productions, the use of fingerprints, blood, and signatures in art, and bodily tattoos (Neef et al. 2006). One of the co-editors of this volume, a media scholar, is also the author of a monograph on mediated memories speculating how documentary forms or objects, such as diaries and blogs, music recordings, and photographs are in constant flux and the implications of this on personal memory (van Dijck 2007). In both cases, we can both see new opportunities for archivists to engage in a vigorous, stimulating scholarship and how archivists have already influenced scholarship beginning to investigate staid, taken-for-granted documentary forms (such as the letter).

\section{References}

Alexander B (2008) 'For posterity': the personal audio recording of Louis Armstrong. Am Arch 71:50-56 Bell G, Gemmell J (2009) Total recall: how the e-memory revolution will change everything. Dutton, New York

Benson AC (2009) Killed negatives: the unseen photographic archives. Archivaria 68:1-37 
Caswell M (2009) Instant documentation: cell-phone-generated records in the archives. Am Arch 72:133145

Cook T (2009) The archive(s) is a foreign country: historians, archivists, and the changing archival landscape. Can Hist Rev 90:497-534

Cox RJ (2009) Digital curation and the citizen archivist. In: Tibbo H et al (eds) Digital curation: practice, promises and prospects. School of Information and Library Science, Chapel Hill, pp 102-109

Darnton R (2009) The case for books: past, present and future. Public Affairs, New York

Davies E (2008) The script as mediating artifact in professional theater production. Arch Sci 8:181-198

Deresiewicz W (2009) The End of Solitude (in our fast-paced, hyper-networked digital world), Chronicle of Higher Education, The Chronicle Review Volume 55, Issue 21, p. B6., available at http:// chronicle.com/free/v55/i21/21b00601.htm

Dierks K (2009) In my power: letter writing and communications in early America. University of Pennsylvania Press, Philadelphia

Douglas J, MacNeil H (2009) Arranging the self: literary and archival perspectives on writers' archives. Archivaria 67:25-39

Dover PM (2007) Deciphering the diplomatic archives of fifteenth-century Italy. Arch Sci 7:297-316

Florey KB (2009) Script and scribble: the rise and fall of handwriting. Melville House Publishing, Brooklyn

Freeman J (2009) The tyranny of e-mail: the four-thousand year journey to your inbox. Scribner, New York

Garvey M (2009) Stylized: a slightly obsessive history of Strunk \& White's The elements of style. Simon $\&$ Schuster, New York

Gerber DA (2006) Authors of their lives: the personal correspondence of British immigrants to North America in the nineteenth century. New York University Press, New York

Gilliland A, McKemmish S (2004) Building an Infrastructure for archival research. Arch Sci 4:149-197

Gilliland-Swetland A (1995) Digital communications: documentary opportunities not to be missed. Arch Issues 20(1):39-50

Golden CJ (2009) Posting it: the Victorian revolution in letter writing. University Press of Florida, Gainesville

Goodman D (2009) Becoming a woman in the age of letters. Cornell University Press, Ithaca

Hyry TH, Onuf R (1997) The personality of electronic records: the impact of new information technology on personal papers. Arch Issues 22(1):37-44

Jones S, Abbott D, Ross S (2009) Redefining the performing arts archive. Arch Sci 9:165-171

Lanier J (2010) You are not a gadget: a manifesto. Alfred A. Knopf, New York

Mallon T (1984) A book of one's own: people and their diaries. Hungry Minds Publishing, New York

Mallon T (2009) Yours ever: people and their letters. Pantheon Books, New York

Mifflin J (2007) Visual archives in perspective: enlarging on historical medical photographs. Am Arch 70:32-69

Mifflin J (2009) 'Closing the circle': Native American writings in Colonial New England, a documentary nexus between acculturation and cultural preservation. Am Arch 72:344-382

Morello R, Morrison AD (eds) (2007) Ancient letters: classical and late antique epistolography. Oxford University Press, New York

Murray S (2008) From album to archive: context, meaning, and two photographic albums from an India mission. Archivaria 65:39-60

Neef S, van Dijck J, Ketelaar E (2006) Sign here! Handwriting in the age of new media. Amsterdam University Press, Amsterdam

O'Shaughnessy M (2008) Just write: the art of personal correspondence. Gibbs Smith, Salt Lake City

Parrish SS (2007) American curiosity: cultures of natural history in the colonial British Atlantic world. Published for the Omohundro Institute of Early American and Culture by University of North Carolina Press, Chapel Hill

Poster C, Mitchell LC (eds) (2007) Letter-writing manuals and instruction from antiquity to the present: historical and bibliographic studies. University of South Carolina, Columbia

Ricci S (2008) Saving, rebuilding, or making: archival (re)constructions in moving image archives. Am Arch 71:433-455

Saltzman G (2008) Old masters, new world: America's raid on Europe's great pictures 1880-World War I. Viking, New York

Shepherd M, Hogan S (2008) The art of the personal letter: a guide to connecting through the written word. Broadway Books, New York 
Society of American Archivists (2002) Guidelines for a graduate program in archival studies. http://www.archivists.org/prof-education/ed_guidelines.asp. Accessed 29 June 2010

Solomon SJ (1998) Corresponding effects: artless writing in the age of e-mail. Mod Age 40:319-323

Thompson C (2010) Floating signifiers: the Internet hasn't killed the English language-yet, BookForum 16 (February/March 2010): 12

Van Dijck J (2007) Mediated memories in the digital age. Stanford University Press, Stanford Wright K (2009) Recording 'a very particular Custom': tattoos and the archive. Arch Sci 9:99-111

\section{Author Biography}

Richard J. Cox is a Professor in Library and Information Science at the University of Pittsburgh, School of Information Sciences where he is responsible for the archives concentration in the Master's in Library Science degree and the Ph.D. degree. He was a member of the Society of American Archivists Council from 1986 through 1989. Dr. Cox also served as Editor of the American Archivist from 1991 through 1995 and Editor of the Records \& Information Management Report from 2001 through 2007. He has written extensively on archival and records management topics and has published fourteen books in this area: American Archival Analysis: The Recent Development of the Archival Profession in the United States (1990) - winner of the Waldo Gifford Leland Award given by the Society of American Archivists; Managing Institutional Archives: Foundational Principles and Practices (1992); The First Generation of Electronic Records Archivists in the United States: A Study in Professionalization (1994); Documenting Localities (1996); Closing an Era: Historical Perspectives on Modern Archives and Records Management (2000); Managing Records as Evidence and Information (2001), winner of the Waldo Gifford Leland Award in 2002; co-editor, Archives \& the Public Good: Records and Accountability in Modern Society (2002); Vandals in the Stacks? A Response to Nicholson Baker's Assault on Libraries (2002); Flowers After the Funeral: Reflections on the Post-9/11 Digital Age (2003); No Innocent Deposits: Forming Archives by Rethinking Appraisal (2004), winner of the Waldo Gifford Leland Award in 2005; Lester J. Cappon and Historical Scholarship in the Golden Age of Archival Theory (2004); Archives and Archivists in the Information Age (2005); Understanding Archives \& Manuscripts (2006) with James M. O'Toole; Ethics, Accountability, and Recordkeeping in a Dangerous World (2006); and Personal Archives and a New Archival Calling: Readings, Reflections and Ruminations (2008). A new book, The Demise of the Library School: Personal Reflections on Professional Education in the Modern Corporate University, will be published later in 2010. Dr. Cox was elected a Fellow of the Society of American Archivists in 1989. 